\title{
La violencia como respuesta a la exclusión: producción de subjetividades juveniles en sectores populares (Córdoba, Argentina)*
}

\author{
Violence as a Response to Exclusion: Production of Youth \\ Subjectivities in Low-Income Sectors
}

A violência como resposta à exclusão: produção de subjetividades juvenis em setores populares (Córdoba, Argentina)

\section{Lic. Francisco Ghisiglieri** y Dra. Griselda Cardozo***}

\section{RESUMEN}

El presente artículo se propone abordar la compleja interrelación entre jóvenes de sectores populares y la violencia, desde una perspectiva que pone como eje al sujeto en su relación con el contexto social. Para tal fin, se presentan resultados de una investigación de tipo cualitativo, llevada a cabo con jóvenes de un barrio popular de la ciudad de Córdoba, Argentina. Se realizaron registros de observación y análisis de fuentes secundarias.

El trabajo permitió dar cuenta del modo en que la violencia se articula en un contexto en el que se conjugan desigualdad social, discriminación y exclusión. Además, visibilizar la relación entre la violencia y los procesos de subjetivación en curso. En un contexto de disolución de vínculos y de falta de oportunidades, los jóvenes encuentran en la violencia un último recurso para constituirse como sujeto.
Palabras clave: joven, violencia, exclusión social, subjetividad.

Este artículo deriva de la tesis doctoral "Procesos de subjetivación de jóvenes en condiciones de pobreza en un barrio de la Ciudad de Córdoba (Argentina)", radicada en la Facultad de Psicología de la Universidad Nacional de Córdoba, con beca cofinanciada por la Universidad Católica de Córdoba y el CONICET (2014-2019).

Argentino. Instituto de Investigaciones Psicológicas (CONICET-UNC), Facultad de Psicología, Universidad Católica de Córdoba. E-mail: franciscoghisiglieri@gmail.com *** Argentina. Instituto de Investigaciones Psicológicas (CONICET-UNC), Facultad de Psicología, Universidad Católica de Córdoba. E-mail: griseldacardozo656@hotmail.com 


\begin{abstract}
This paper aims to address the complex interrelation that exists between young people from low-income sectors and violence, from the perspective of the subject and his or her relationship to the social context. To this end, it presents the results of a qualitative research study carried out with young people from a lowincome neighborhood in the city of Cordoba (Argentina), including participant observation and analysis of secondary sources.

The analysis shows how violence is articulated in a social context in which inequality, discrimination and exclusion are combined. In addition, it highlights the relationship between violence and the processes of subjectification at play. In a context of dissolving social ties and lack of opportunities, young people find in violence a last resort to become subjects.
\end{abstract}

\section{RESUMO}

Este artigo visa abordar a complexa inter-relação entre jovens de setores mais modestos e a violência, a partir de uma perspectiva que coloca o sujeito como ponto central em sua relação com o contexto social. Para isso, apresentamos os resultados de uma investigação do tipo qualitativa, realizada com jovens de um bairro popular da cidade de Córdoba, na Argentina. Foram feitos registros de observação e análise de fontes secundárias.

O trabalho permitiu explicar a forma como a violência se articula em um contexto no qual desigualdade social, discriminação e exclusão se conjugam. Além disso, torna visível a relação entre a violência e os processos de subjetivação em curso. Em um contexto de dissolução de vínculos e de falta de oportunidades, os jovens encontram na violência um último recurso para se constituírem como sujeitos.
Key words: Youth, violence, social exclusion, subjectivity

Palavras-chave: jovem, violência, exclusão social, subjetividade. 


\section{Introducción}

Los resultados que se presentan en este trabajo forman parte de un proyecto de investigación más amplio, cuyo objetivo general fue analizar los procesos de subjetivación de jóvenes en condiciones de pobreza en un barrio de la ciudad de Córdoba (Argentina), al que llamaremos "Villa Cañada”. El avance en la construcción y el análisis de datos nos llevó a comprender que la violencia ocupaba un lugar central en sus procesos de subjetivación y, en consecuencia, nos condujo a elaborar las primeras preguntas que fueron guiando este tramo de la investigación: ¿qué lugar ocupa la violencia en la construcción de las subjetividades de estos y estas jóvenes? ¿Por qué cobra la importancia que se percibe en sus vidas cotidianas?

En este marco, nos propusimos problematizar la compleja interrelación entre la producción de subjetividades juveniles de sectores populares y la violencia. Pensar en esta interrelación es una tarea compleja, ya que obliga a analizar cómo la violencia se entrelaza en un contexto más amplio de desigualdad social, discriminación y exclusión. La violencia se conjuga en estos casos con la precariedad en la que construyen sus subjetividades los y las jóvenes de sectores populares de Córdoba ${ }^{4}$ (Cardozo, 2015; Ministerio de Trabajo, Empleo y Seguridad Social, Presidencia de la Nación, 2018; Cardozo, Dubini y González, 2019). Tal y como venimos asistiendo también en otros contextos latinoamericanos, estas condiciones de desigualdad y precariedad modelan las prácticas juveniles referidas a la violencia (Reguillo, 2008; Míguez, 2010; Auyero y Berti, 2013).

Además, requiere de un ejercicio de deconstrucción de las discursividades que, creadas y recreadas desde el "mundo adulto", definen a la juventud como un "problema" (Nateras, 2016). Sin duda, estas prácticas se ven recrudecidas cuando se trata de jóvenes pobres, quienes se vuelven los principales destinatarios de dispositivos que los definen como "peligrosos", "apáticos" e "incapaces" (Chaves, 2005).

En cambio, es necesario "situar" a estos jóvenes, anclarlos a sus contextos económicos, políticos, culturales; al tiempo histórico que les 
toca vivir y al espacio que habitan; alejados de determinismos, con el fin de entender y comprender su singularidad a partir de la diversidad de sus prácticas sociales (Nateras, 2016), atendiendo a los modos en que, en su cotidianeidad, se enfrentan a las complejas condiciones en que construyen sus subjetividades. No estamos ante una población homogénea, sino ante múltiples formas de ser joven (Chaves, 2010; García Canclini, Cruces y Urteaga, 2012).

A tono con la necesidad de un análisis situado de las prácticas juveniles, tomamos para este trabajo herramientas conceptuales de los desarrollos foucaultianos sobre los procesos de subjetivación (Foucault, 1988, 2007, 2008), en articulación con las conceptualizaciones propuestas por Wieviorka referidas a la violencia (Wieviorka, 2006).

Con relación a la noción de "subjetivación", es posible distinguir en ella un sentido amplio y un sentido estricto (Castro, 2011). En sentido amplio, Foucault entiende a la subjetivación como el modo en que se producen subjetividades en el doble movimiento de objetivación por determinados dispositivos de saber-poder y resistencia a estos dispositivos (Foucault, 2007, 2008). A su vez, en sentido estricto, Foucault entiende por modos de subjetivación los procesos en los cuales un sujeto se constituye en sujeto moral; son formas de actividad sobre sí mismos que responden a la capacidad que tiene un sujeto de autoafectarse (Foucault, 1988).

Consideramos que este sentido estricto de subjetivación se articula con los desarrollos de Wieviorka (2006) sobre la violencia. Wieviorka sostiene que es posible comprender a la violencia más allá de los desarrollos que la reducen al cálculo instrumental o a la crisis de un sistema: la violencia puede ser entendida, también, como la antítesis del conflicto, su negación y, en última instancia, una negación del sujeto mismo, así como un intento de restitución subjetiva. Es decir, Wieviorka plantea que la violencia puede ser comprendida como una forma de destituir la capacidad de autoafectación del sujeto (desubjetivación); o bien, como una respuesta a esta negación, como un modo de restituir esa capacidad del sujeto (subjetivación).

De un modo general, sostenemos la hipótesis que, en estos contextos, la violencia emerge como un modo de respuesta de los y las jóvenes ante el no reconocimiento, el rechazo, la discriminación, en 
suma, ante la negación de sus subjetividades. Por lo que consideramos necesario analizar e interpretar la violencia en su doble movimiento: como una práctica de subjetivación y como práctica de desubjetivación (Wieviorka, 2006).

En esta línea, nos proponemos indagar, en el caso de un barrio de la ciudad de Córdoba, cómo la violencia se entrama en un contexto de exclusión social; cómo se transforma, para los y las jóvenes, en una matriz de desubjetivación, condicionando las más diversas relaciones cotidianas en el barrio; y cómo, en este escenario, devenir violento emerge como una forma de subjetivación posible.

\section{Metodología y escenario de investigación}

El diseño metodológico de este estudio, de tipo cualitativo, se centró en un trabajo de campo que se llevó adelante en el periodo 2013-2017, en Villa ${ }^{5}$ Cañada (Córdoba, Argentina). Articuló la observación participante y el análisis de fuentes secundarias. Con esta triangulación se buscó adoptar un "punto de vista nómada que sea capaz de desplazarse por diferentes niveles, lugares, discursos" (Reguillo, 1999, p. 237). Ir más allá de la mirada intracomunitaria, pero sin negarla, ya que el objetivo fue visibilizar la articulación de estas prácticas cotidianas con su contexto social más amplio.

La observación representó una vía de acceso y de construcción de datos referidos a la dimensión de análisis en la que se articula el dispositivo social y la vida cotidiana de los/las jóvenes, para dilucidar, desde allí, cómo se construyen subjetividades en el territorio (Grinberg, 2015). El análisis de fuentes secundarias, por su parte, se centró en noticias periodísticas, documentos gubernamentales y de difusión de organizaciones sociales y políticas. Estas fuentes permitieron principalmente triangular la información producida desde el terreno.

El escenario de observación privilegiado fue un proyecto socioeducativo ubicado en Villa Cañada: un espacio laico, perteneciente a una fundación católica, en el cual participan aproximadamente 60 niños,

"Villas de emergencia" o "villas miserias" es el nombre que reciben en las grandes ciudades de Argentina los barrios con infraestructuras precarias. De acuerdo con un relevamiento realizado por la ONG Techo (2016), en la ciudad de Córdoba hay 134 villas, en las que viven 21.300 familias. 
niñas y jóvenes de entre 6 y 18 años, quienes asisten regularmente al apoyo escolar y a otras actividades socioeducativas. También participan familiares y personas allegadas del barrio, que asisten a reuniones, encuentros y eventos comunitarios ocasionales. Durante el periodo mencionado (2013-2017), uno de los integrantes del equipo de investigación participó activamente del proyecto y realizó talleres junto con los y las jóvenes (de memoria colectiva, de cartografía, taller de radio).

Además, se realizaron observaciones en otros espacios que pudieran proveer mayor información sobre las condiciones de vida de los y las jóvenes: reuniones de consejos gubernamentales referidos a infancia y juventudes; redes de articulación de organizaciones regionales, así como de otros espacios habitados de manera privilegiada por jóvenes - como el club barrial-.

Villa Cañada es una villa en proceso de urbanización, ubicada a los márgenes de una ruta nacional, en uno de los ingresos a la ciudad. Desde 2008 es beneficiaria de un programa provincial de mejoramiento barrial, alcanzando grados de urbanización dispares: en su mayoría, servicios que de hecho se brindan, pero de forma informal y precaria. Ese mismo año, con motivo del anuncio del mencionado programa, se reconocían 326 familias habitando el lugar. Cuenta con una rica historia en términos de procesos comunitarios e intervenciones estatales. De acuerdo con los datos relevados, sus orígenes se remontan a un grupo de personas que provenían del interior provincial o de otras provincias, y que llegaron a la ciudad, en general, en busca de trabajo y de mejorar sus condiciones de vida.

Para la realización del trabajo se tomaron los recaudos éticos pertinentes. A fin de resguardar el anonimato, se modificó toda información que permitiera identificar a las personas que participaron de la investigación.

\section{La juventud de Villa Cañada, entre la violencia policial y la exclusión territorial}

En la madrugada del sábado 24 de octubre de 2015, en el límite de Villa Cañada, encuentran muerto a un joven. En sus primeras declaraciones mediáticas, el fiscal de la causa se apresura a decir que las razones "están claras". Se trataría de un hecho de "legítima defensa privilegiada": 
este joven habría ingresado con intenciones de robo a una vivienda, el dueño de la casa escucha ruidos y se da "una lucha con cuchillos" en la que el "delincuente" es "quien se lleva la peor parte".

Sin embargo, este episodio habría concluido con el joven herido, pero quienes lo encuentran al día siguiente, denuncian que ha muerto. Un militante social afirma en otro medio de comunicación que, después del altercado en la vivienda, "la policía lo retira al ladrón, pero todavía vivo, y cuando lo devuelve, lo devuelve sin un ojo, visiblemente golpeado y muerto", versión que coincidiría con la de Norma, una vecina del lugar, con quien conversamos en un recorrido barrial el día siguiente: la autopsia habría confirmado que estaba todo golpeado, "hasta los testículos", y efectivamente le habían sacado un ojo. Así lo dejaron en la puerta de su casa. Además, aporta la información que el joven asesinado tenía vínculos importantes con un narcotraficante de la zona.

La confusión del altercado se produce en el marco de una larga tradición de injusticias y abusos policiales, lo cual provoca indignación y rabia en la comunidad. En este clima, el lunes, familiares, vecinos y una organización social realizan un reclamo pidiendo justicia y que se esclarezca el crimen. La estrategia de visibilización y ejercicio de fuerza a la que recurren es la más usual para este barrio: el corte de la ruta nacional aledaña.
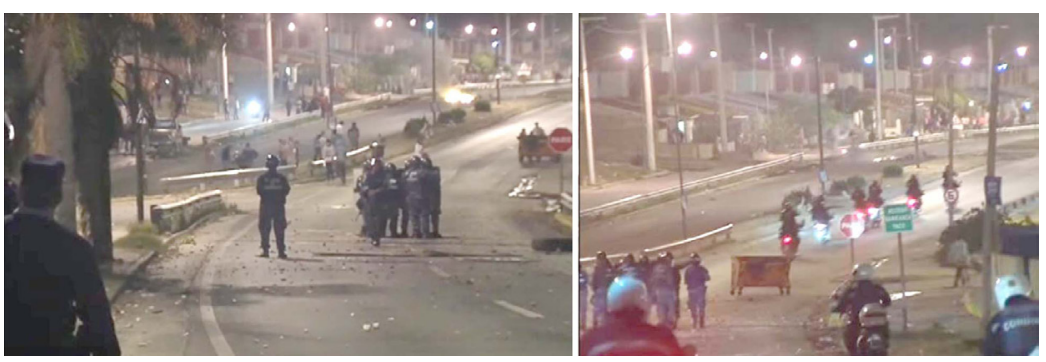

Figura 1. Fotografías del día de protesta y represión policial (extraídas del vídeo: Canal 10 Córdoba, 27 de octubre de 2017).

Mientras se desarrolla la protesta, llega la guardia de infantería de la Policía Provincial al corte de ruta y comienza una feroz represión que dura prácticamente todo el día. A horas de la noche, con cara de agobio, el comisario encargado del operativo declara ante un periodis- 
ta televisivo: "Seguimos trabajando para brindar tranquilidad acá (...) Es una ruta, y tenemos que tenerla liberada a la ruta, vamos a intentar que la gente se tranquilice y no tener lesionados de ninguna parte (...)". Ante la pregunta del periodista por la situación, explica que "La gente está exaltada por lo que ha pasado con esta persona el fin de semana". Por ende, su misión es tranquilizarla.

Sin embargo, el método utilizado para "lograr la tranquilidad para el sector" es una violenta represión.

(Maite Amaya, militante social): La policía arremetió con todo, reprimieron a más no poder. Entraron a la casa de una de las compañeras, a varias casas, donde estaban refugiados compañeros que estaban colaborando con los pibes que estaban siendo baleados, porque fue una balacera terrible, apuntaban a hacer una masacre (...) Hay personas heridas, tenemos compañeras que han entrado a cirugía, han sido baleadas y apaleadas por la policía adentro de su casa, en la cocina de su casa, mientras tiraban tiros (...) es una balacera, estamos siendo carne de cañón de una balacera terrible, de una represión increíble que no tiene ningún tipo de justificación, no la legítima nada. Esto es una violación total, algo inhumano, esto no se puede hacer. (Mucho Palo Noticias, 26 de octubre de 2015, párr. 3)

Un modo represivo que busca acallar a quienes protestan, invisibilizar la situación y, lo que parece ser central, liberar la circulación para quienes transitan por la ruta afectada. Una estrategia que, para buscar "tranquilidad", recurre nuevamente a la violencia.

Lo primero que quisiéramos señalar del episodio relatado es la complejidad de instituciones, organizaciones, prácticas y condiciones que se entraman en este estallido de violencia. Una complejidad de elementos que, si tomásemos cada uno de ellos (redes de narcotráfico, policías, represión, organizaciones sociales, delitos, justicia por mano propia, protestas, marginación, precariedad, circulación de bienes), encontraríamos la punta de un ovillo que nos permitiría abordar el fenómeno desde un enfoque diferente.

En este caso, quisiéramos puntualizar dos dispositivos que observamos como condicionantes de la violencia, tanto en el caso de los y las jóvenes estudiados, como en otros estudios llevados adelante en barrios populares de la ciudad. Dos dispositivos que Cardozo (2015) 
definió como "dispositivos destituyentes" de la subjetividad: el policial, que se ve claramente operando en la represión relatada, y el territorial.


Figura 2. Imagen realizada por el Colectivo Manifiesto y utilizada en la campaña previa a la novena Marcha de la Gorra (2015) en protesta a la violencia policial y estigmatización de la pobreza. Para un análisis de este movimiento social, véase Bonvillani (2015).

Con relación al dispositivo policial, podemos decir que, en la ciudad de Córdoba, la violencia institucional agenciada por la policía hacia los jóvenes tiene una larga y densa historia, la cual incluye detenciones masivas, persecución policial y múltiples situaciones de abuso (Crisafulli y León Barreto, 2015). El punto de partida de esta reorientación de las políticas de seguridad en clave de "tolerancia cero" lo encontramos en 2004, promovida por el Manhattan Institute. Tuvo como soporte un polémico instrumento jurídico que habilitaba las detenciones arbitrarias a través de la figura de merodeo (Crisafulli y León Barreto, 2011). En la actualidad, cuenta con numerosas denuncias por organismos de derechos humanos locales (Comisión Provincial de la Memoria de Córdoba, 2015), e internacionales ${ }^{6}$.

\footnotetext{
$6 \quad \mathrm{Al}$ respecto, en 2017 el informe sobre la situación argentina del Comité contra la Tortura de las Naciones Unidas señalaba: “El Comité se muestra preocupado ante informaciones que dan cuenta de patrones de violencia y arbitrariedad por parte de las fuerzas de seguridad federales y provinciales en el marco de detenciones policiales sin orden
} 
Roberto (Hombre adulto, en relación con su juventud) -La policía te frenaba y te decía:

$-¿$ ¿De dónde sos?

—De Alto General Paz

Chirlo; - ¿De dónde sos?

-De Alto General Paz

Chirlo; - Vos sos de un negro de la villa, ¿de dónde sos?...

Y así hasta que le decías que eras de la villa, si te iban a llevar igual. Si eras de Villa Cañada te llevaban. (Registro de campo, 14 de mayo de 2016)

Este dispositivo se erige en nombre de una política de seguridad y de prevención en la ciudad (Crisafulli, 2014), volviendo a los y las jóvenes víctimas propiciatorias de prácticas de discriminación y diversos tipos de hostigamiento y acoso policial (Bisig, 2014).

Como se puede ver en este fragmento de registro anterior, la práctica policial está íntimamente relacionada con el dispositivo territorial, en tanto son los agentes policiales los principales encargados de imponer "cercos" a los jóvenes de los sectores populares - especialmente varones-, que les impiden aproximarse al centro de la ciudad (Cardozo, 2015).

Entonces, el segundo dispositivo que cobra relevancia, a la hora de comprender la relación de los jóvenes cordobeses con la violencia, es el dispositivo territorial. Los estudios sobre el tema demuestran que, desde hace ya unas décadas, la ciudad de Córdoba viene desarrollando un poderoso dispositivo de control territorial que intervino su tejido sociourbano de manera decidida, construyendo una ciudad atravesada por muros de concreto y simbólicos, cuyo efecto es la fragmentación

judicial, particularmente de jóvenes y menores en situación de marginalidad social, que incluirían detenciones por averiguación de identidad y otras detenciones no vinculadas a conducta delictiva. Según las informaciones recibidas, dichos abusos incluirían tentativas de homicidio, como la de Lucas Cabello, desapariciones forzadas, así como actos de tortura, como los infligidos presuntamente contra Ezequiel Villanueva e Iván Navarro, de 15 y 18 años respectivamente (arts. 2 y 16)" (Observatorio de Derechos Humanos del H. Senado de la Nación Argentina, mayo de 2017, p. 14). 
socioterritorial de la misma (Scribano y Boito 2010; Núñez y Ciuffolini, 2011; Cervio, 2015).

Este dispositivo opera bajo lógicas de exclusión y desprecio de quienes habitan los sectores definidos como "zonas rojas", produciendo resentimiento, rencor y odio, tanto desde los excluidos como desde quienes se vuelven coparticipes de la exclusión y discriminación (Cardozo, 2015).

Juana (mujer adulta) - O sea, a mí no se me complica en ese sentido de dónde vivís, y toda la cosa, pero, por ejemplo, en el hecho de ir a decir a una amiga o una compañera de colegio de mi hija, ahora: "chicas, las invito a mi casa que queda en tal lado"; ;Olvidate! porque no vienen. Inclusive, ahora yo la voy a buscar, amigas tienen que llegan a la casa, pero en mi caso, cuando yo vivía acá que era más chica, ni en un cumpleaños tenía amigos. Todo el cumpleaños eran familiares. Pero... ¿ ipor qué? Me daba vergüenza decir dónde vivía, me daba vergüenza que vinieran a ver mi casa, que vinieran a ver cómo era, ¡Olvidate! Yo nunca en mi vida, excepto ahora, he dicho dónde vivo. $\mathrm{Y}$ he hablado con gente de, que tienen estado económico muy alto, y cuándo tuve la oportunidad de decir, cuando tomé confianza y de decirle dónde vivía, no me creían. (Registro de campo, 1 de noviembre de 2017)

Wacquant ha definido como "estigmatización territorial" al proceso que actúa mediante la representación colectiva ligada a un lugar determinado (Wacquant, Slater y Borges, 2014). De acuerdo con el autor (Wacquant, 2007), con la consolidación de las políticas neoliberales, a la indigencia material y la hostilidad etnorracial se suma el desprecio público hacia los pobladores de los sectores relegados de las megalópolis. Como es de esperar, este estigma implica, para quienes lo padecen, una serie de efectos en sus subjetividades. Uno de estos, sostiene el autor, es el sentimiento personal de indignidad, relacionado aquí con la vergüenza que siente Juana frente a otros conciudadanos por residir en Villa Cañada.

De este modo, podemos ver cómo la vida de estos y estas jóvenes se encuentra atravesada por múltiples violencias (Bourgois, 2001): una violencia estructural referida a la situación de exclusión social y la consecuente desafiliación (Castel, 2012); una violencia política —que podemos ver patentizada en los mencionados instrumentos legales 
cordobeses que habilitan la criminalización de la pobreza-; una violencia simbólica, evidenciada en la legitimación de la desigualdad a través del dispositivo socioespacial, así como las múltiples prácticas de discriminación clasistas y racistas; $y$, por último, una violencia cotidiana que, como veremos a continuación, incluye las múltiples violencias entre pares, de género, hurtos, etc. (Cardozo, 2015).

El saldo de este entramado de condiciones es, como señala Nateras (2016), la producción de subjetividades juveniles "sitiadas". La violencia se encadena con la exclusión, estigmatización y empobrecimiento, delimitando escasas oportunidades para estos y estas jóvenes "invisibles" (Nateras, 2016), y, en última instancia, operando como dispositivos desubjetivantes de las posibilidades de entrar en procesos de subjetivación (Wieviorka, 2006).

\section{La violencia como trazo de lo cotidiano}

La vida cotidiana de las personas, y en especial de los y las jóvenes, de Villa Cañada se ve atravesada por diferentes ejercicios de violencia. Ejercicios de violencia que, por su intensidad y sistematicidad, constituyen un rasgo saliente en la caracterización de las relaciones del lugar: "No tenemos tantos niños que pasen hambre, como niños que diariamente viven violencia en su casa" (Registro de campo, 15 de marzo de 2017), señalaba una profesional de la salud de la zona. El hambre fue una problemática presente en 2001, pero que, gracias a los diferentes programas sociales, se pudo apaciguar. La violencia, en cambio, parece haberse instalado como uno de los grandes problemas del barrio.

Nos sentamos en la placita y nos ponemos a conversar con algunas chicas que van llegando. La conversación inicia con Ana, quien comenta que a una vecina "la hicieron cagar anoche". Luego, otro de los chicos cuenta que a "la Ana" también "la hicieron cagar". Nadie da más detalles, tampoco nadie pregunta, esa descripción parece suficiente. De repente, la conversación se convierte en una sucesión de historias de hechos de violencia guiadas por la idea de "hacer cagar". (Registro de campo, 20 de marzo de 2017)

Lo primero que se debe señalar es la necesaria vigilancia epistémica que requiere el término "violencia". En primer lugar, porque, como señala Di Leo (2011), diferentes agentes definen como inaceptables o 
intolerables ciertas acciones en función de criterios que remiten a lo que podríamos definir como "sensibilidades sociales diferentes". Hay una dimensión de la significación de "violencia" que está en disputa. Esto se puede ver de un modo esperable entre agentes internos y externos a la comunidad. Por ejemplo, la profesional de la zona, antes mencionada, señalaba: "Lo que sí veo es que el trato de ellos es con mucha violencia. Está naturalizado, como algo normal, desde la cachetada que le pegan hasta el tirón del brazo" (Registro de campo, 15 de marzo de 2017). En este caso, hay una mirada externa, de otro grupo social, con otras disposiciones culturales, que identifica un modo de relacionarse con el cuerpo del otro y lo define como "violento". Aquí el riesgo es realizar un análisis, desde un punto de vista etnocéntrico, que objetive lo que se entiende por "violencia" desde parámetros de otro grupo social.

Dicho esto, la segunda cuestión importante es la referida al estatuto que tiene la violencia en las relaciones cotidianas. En diálogo con la perspectiva de las personas del barrio, entendemos que esta violencia sistemática adquiere un lugar bastante particular, que deberíamos ubicar entre lo cotidiano pero no inadvertido, y lo problemático pero no del orden del horror.

Yohana (joven) - iQué anotas?

Investigador - Registro lo que hacen.

Yohana $-i$ Y qué ves?

Investigador -Que algunos hacen las tareas, que otros charlan...

Yohana -Otros pelean. (Registro de campo, 18 de marzo de 2013)

El pelear, así como el "portarse mal", el "joder", el "hacer bardo" y las múltiples formas que adquiere esta violencia sistémica no constituyen un hacer cotidiano que pase absolutamente inadvertido, como sostuvieron, por ejemplo, Duschatzky y Corea (2002). Estas autoras, en su análisis de procesos de subjetivación de jóvenes cordobeses de sectores populares, sostuvieron que, al no haber legalidad, no había reconocimiento de la infracción. Como se puede ver en la escena anterior, la propuesta del observador, de negar la situación, no logra consolidar un pacto con la joven con quien interactuaba, quien no duda en afirmar: "otros pelean". Entonces, si bien la violencia posee una presencia insoslayable en la cotidianeidad de la villa, no podemos decir que se trate de una interacción totalmente naturalizada. 
Sin embargo, tampoco podemos decir que, incluso en situaciones de violencia extrema, se trate necesariamente de una situación que sea vivida en términos de lo horroroso:

Se aproxima la madre de Constanza, Selena. Mientras hacemos la inscripción al apoyo escolar, conversamos. Me cuenta que está criando sola a Constanza. Su padre está preso, ella misma lo denunció. La situación que desencadenó la denuncia fue una discusión en la que él le pegó seis puñaladas. Esto fue el año pasado. Tiene cinco hijos y los mantiene a todos ella sola, saliendo a pedir. (Registro de campo, 14 de abril de 2014)

En este caso, Selena narra el episodio sin mostrar alteraciones emocionales, ni intenciones de velar o disminuir la intensidad del hecho. Tampoco se evidencian signos de algún tipo de preocupación por Constanza, quien debe asimilar la situación de que su padre apuñaló a su madre y la intentó asesinar, así como que ahora se encuentra en prisión. Es llamativo también que la conversación se da sin tener ningún vínculo previo con su interlocutor, y en una relación sumamente ocasional con la institución.

Entonces, esta experiencia de convivencia con la violencia no la ubica ni en un lugar en el cual queda como totalmente naturalizada, que pase inadvertida, ni tampoco en el lugar de lo horroroso, de lo traumático. Más bien, se configura como parte de una realidad con la que, indefectiblemente, la construcción subjetiva juvenil tiene que lidiar.

Mientras esperamos para ingresar al apoyo, veo que Moisés tenía a Enzo agarrado del cuello por la espalda:

Moisés - Y cuando te agarren así, ¿qué vas a hacer?

Enzo - Y le voy a pegar con el codo así (y simula un golpe a las costillas con el codo).

Investigador —¿Cómo “cuando te agarren asi”"?! ¡¿Por qué lo van a agarrar?!

Moisés -Y sí profe... en una pelea. (Registro de campo, 18 de noviembre de 2015)

Las situaciones que se suceden, que pueden implicar golpizas, violaciones, incluso hechos de tortura $-\mathrm{y}$ que desde luego no afectan a 
toda la población - forman parte de lo posible, de las "cosas que pasan" en el barrio.

Desde la mirada de estos jóvenes hay un diagnóstico de base: en algún momento será necesario pelear. Para cuando llegue ese momento, es necesario estar preparado. Será necesario saber pelear, saber defender la integridad, pero sobre todo la reputación: "hacerse respetar".

Al ver que un niño, Raúl, a quien habían amenazado toda la tarde, ya no estaba en la sala, dejo de registrar y salgo rápidamente del apoyo escolar. Veo a uno de los chicos más grandes, Jonathan, quien había aparecido por la ventana en el momento de las amenazas, sosteniendo por la espalda a Raúl, quien de a poco se caía y arrojaba patadas a un charco. Juancito, el agresor, se había alejado un poco del lugar, pero no se retiraba del todo.

Me acerco e intento separarlos, pero noto que en realidad Jonathan lo estaba sosteniendo porque Raúl estaba muy nervioso: seguía arrojando patadas, tenía todo el cuerpo sumamente tenso, las manos contraídas y hacía algún ruido con la boca. Me sumo a los intentos de su compañero de calmarlo. (Registro de campo, $18 \mathrm{de}$ marzo de 2013)

Las amenazas con la que conviven los y las jóvenes, la posibilidad de una golpiza, de ser discriminados/as o arrestados (en el caso de los varones) trae aparejada la necesidad de una alarma constante que permita evitar potenciales hechos dolorosos. Hay una reconfiguración del conjunto de conductas que se debe hacer en función de este autocuidado constante.

Otra cuestión importante a señalar es que las instituciones no significan, por sí mismas, ni una protección suficiente frente a la violencia, ni un tope a su ejercicio. El conflicto familiar o barrial se instala en las instituciones, y viceversa, en un desplazamiento casi sin alteraciones. El sujeto devenido "joven violento" ingresa a las instituciones sin ningún tipo de transformación en su rol social.

Jeremías (joven) me cuenta que tiene un "puntal" —así le llama él-. Lo lleva en la muñeca, escondido en la campera.

Investigador - ¿Por qué?

Jeremías - ... 
Investigador $-i$ Está complicada la calle?

Jeremías - Ayer anduvimos por allá atrás, ahí lo llevé.

Esta situación me trae el recuerdo de un texto de Lewkowicz (2004) que había leído, y que relata la situación de una escuela donde se invitaba a los estudiantes a dejar sus armas antes de ingresar a la institución. Entonces se me ocurre proponerle lo mismo a Jeremías, a través de una dramatización:

Investigador - Bueno, a ver, volvamos a empezar. Salgamos todos y vos Ramón (otro joven) actúa de puerta. Jeremías se para afuera.

En esta ocasión, le pregunto:

Investigador -Jeremías, ¿tiene algún puntal o chicle que tenga que dejar antes de entrar a la escuelita?

Jeremías - Sí, esto (me muestra el famoso puntal, era un cuchillo todo herrumbrado).

Lo invito a que dejé el "puntal" en el armario. Lo hace e ingresa. (Registro de campo, 22 de agosto de 2017)

Es interesante que, desde su imaginario, "la escuelita" - como llaman al apoyo escolar en el barrio- es una continuidad de "la parte de atrás del barrio". El estar allí no significaba que la protección podría radicar en algún otro, sino que aún tenía que llevar su "puntal". El texto de Lewkowicz (2004), al que se alude en el registro, se refiere a situaciones en las cuales las condiciones que posibilitaban el acto educativo no estaban garantizadas, por lo que era necesario desarrollar estrategias que las originaran. En este caso, la asunción de una asimetría que garantice la posibilidad de dejar de estar cuidándose y poder estudiar. Esto se vuelve posible porque existe alguna confianza en la institución, pero debe ser reafirmada en un acto y una negociación entre los actores de esa institución.

\section{La violencia como una forma de subjetivación (posible)}

La violencia adquiere tal magnitud que pareciera responder a una lógica propia. De a momentos, simplemente circula, como si tuviese una fuerza que se retroalimenta a sí misma. Entendemos que esta retroali- 
mentación se relaciona con los dispositivos analizados, pero que también los exceden en tanto se instalan como modos de vinculación que los mismos sujetos reproducen en su vida cotidiana.

Una de las circunstancias que condicionan este hecho es que muchas veces, como hemos visto, frente a los agravios, la acción defensiva o simplemente reactiva recurre a los mismos modos de los que se defiende. Es decir, para limitar el ejercicio de la violencia se recurre al ejercicio de la misma violencia que se busca combatir, asegurando de este modo las bases para una reproducción potencialmente interminable de la misma.

Agustina (joven) cuenta una historia en la cual una compañera la "bolaceó" por Facebook, tratándola como "puta". Esto causa risas en el resto de las chicas, y la corrección de que en realidad le dijo: "perra". Después ella la encaró y le dijo que se lo diga en la cara, que la "iba a hacer cagar".

Investigador $-i$ La peleas para hacerte respetar?

Agustina -Y sí.

Investigador $-i$ Y no se te ocurre otra forma?

Agustina -Y no.

Investigador —Pero así, es violencia por violencia.

Luego de un breve silencio, Agustina se va. (Registro de campo, 20 de marzo de 2017)

Si entendemos que la violencia se da sobre la ausencia de otras regulaciones de conductas, ello insta a que sea la misma violencia el método para restituir alguna legalidad. La golpiza efectiva o su amenaza, así como el grito o la intimidación, representan en muchos casos una forma de ganarse "respeto", de evitar maltratos y abusos. Además, genera condiciones para liderazgos autoritarios y personalistas, agenciados por quien logre acumular respeto por sus capacidades de posicionarse en el campo, muchas veces recurriendo al ejercicio de la violencia (en la línea de lo refiere Bourgois [2010] en su trabajo en un barrio de Nueva York).

La violencia, en este sentido, puede representar una estrategia para conseguir reconocimiento (Zizek, 2009), pero a la vez niega el recono- 
cimiento de los demás. Esta demanda de respeto plantea una situación tramposa, en la cual el camino elegido para conseguirlo implica necesariamente la negación del respeto del otro (Antillano, 2016).

De esta manera, en el contexto de un barrio que se configura como un gran territorio de disputas, la violencia se convierte en un elemento ordenador de los recorridos posibles, las zonas accesibles, las protecciones y las exclusiones. Estas definiciones se relacionan con conflictos intrabarriales actuales o históricos (disputas, asesinatos, etc.), aunque también, como puede apreciarse en el siguiente registro, puede tratarse de definiciones móviles, que llevan la necesidad de realizar un cálculo constante de cómo y por dónde moverse en cada momento.

Nos encontramos con Lucas (joven) ingresando al barrio, cuando me indica que vayamos por un pasillo.

Lucas -Es que por allá tengo un bardo. No paso porque me olvidé el arma... y porque estoy con mi hija. Si no voy por allá.

Investigador $-i Y$ qué bardo tenés?

Lucas - No traje el "chumbo", está en casa, sino voy por allá.

Nos encontramos con otros jóvenes. Están sentados al costado del aguaducho, en el pasto. Tienen sus ojos rojos y están comiendo unas galletas. No se saludan, sino que Lucas les explica que no pasa por el puente, porque no trajo el arma. Los otros sonríen y me piden una naranja.

Lucas - No, que son mías.

Ricardo (joven) - Bueno, dame una, dale.

Lucas - No, no. (Registro de campo, 2 de junio de 2016)

Lo sistemático de la violencia expone a los y las jóvenes a un contexto que se presenta como un gran campo de batalla, y frente al cual, devenir violento - portar un arma, "hacer cagar" - emerge como una forma de restituirse como sujeto. Consideramos que, desde aquí, la necesidad de "hacerse respetar" se puede comprender, en última instancia, como uno de los pocos modos que encuentran para conservar su dignidad frente a agravios, humillaciones, hostigamientos a los que se ven enfrentados a diario: por los dispositivos policiales, por la exclusión de derechos, por la estigmatización y, también, por la violencia entre pares e intracomunitaria. 
Para retomar y profundizar el postulado de que, en este devenir violento, los y las jóvenes encuentran un modo de subjetivación posible, se relatan a continuación dos conversaciones que tuvieron lugar el día siguiente de la jornada represiva narrada en el apartado: "La juventud de Villa Cañada, entre la violencia policial y la exclusión territorial".

En primer lugar, una señora, que habla desde el interior de su casa, a través de las rejas que tiene en su puerta de ingreso. Comenta que se "escucharon tiros hasta tarde", pero que, al momento de esta conversación, estaba todo más calmo. A lo largo del diálogo, fuimos co-construyendo con esta vecina alguna idea que permitiera entender las condiciones que daban lugar a lo que estaba sucediendo. La conclusión a la que arribamos se puede interpretar en la línea de lo que Antillano (2016) define como una de las explicaciones posibles de la violencia: como una expresión de la desintegración social que ha sufrido la villa en los últimos años. Diversas intervenciones estatales en el barrio implicaron el traslado y el desarraigo de muchas familias, lo cual rompió con cierta familiaridad vecinal, con una trama de confianza y, sobre todo, con el reconocimiento mutuo que condicionaba otra convivencia posible.

Una segunda conversación, en este caso con dos jóvenes, da cuenta de una posición que se contrasta en varios puntos con la anterior y que permite vislumbrar esta otra configuración subjetiva, y, por ende, otra forma de comprender la violencia: no como una expresión de la desintegración social, sino, en la línea de lo que venimos planteando, como un modo de lidiar con la violencia social, un modo de sobreponerse a un contexto destituyente, de no dejarse subyugar.

Lucrecia (joven) - Nosotras estuvimos ayer todo el día viendo, hasta la noche, viendo cómo se daban. Era una batalla eso.

Investigador $-i$ Y ustedes qué hacían?

Lucrecia -Y... estábamos sentadas en un costado, viendo. Si estaban todos los negros ahí, estaba mi hermano, mis primos, todos.

Yanina (joven) -Sí, a mi hermano le dejaron una bala adentro.

Lucrecia - La cana estaba con balas de gomas, pero los negros no, tenían balas de en serio. Les tiraban piedras también. En un momento le pegó a uno en la cabeza así, lo golpeó todo. (Registro de campo, 28 de octubre de 2015) 
En este caso, encontramos una subjetivación que logra erigirse por fuera de la encerrona del miedo: si la mujer adulta miraba el barrio a través de las rejas de su casa, estas jóvenes están en la calle, dentro de la escena, "todo el día viendo". Además, es un modo de subjetivación que se asienta en su pertenencia barrial con mayor implicación: los "negros" son sus hermanos, familiares, parte de un grupo social en el que se reconocen. Representan un próximo/prójimo. Por último, una forma de subjetivarse que les permite "resistir" la represión y la invisibilización que los niega como sujetos. Un modo de subjetivación que, entonces, los expone a una convivencia con la violencia que se incrusta en sus cuerpos como "balas", pero que, a su vez, les posibilita sostener una actitud de disputa, de no resignación frente a las injusticias y abusos: son cuerpos en batalla.

En función de lo analizado, podemos ver cómo la violencia condiciona los modos de relacionarse, afectando los más diversos vínculos de los y las jóvenes, así como sus actitudes posibles. Se puede devenir violento o devenir violentado, se puede hacer un uso estratégico de esa violencia o se puede cercar el territorio próximo para mantenerla lo más alejada posible, se puede tomar posiciones diferentes, pero lo que no parece posible es serle totalmente indiferente. En este contexto, entendemos que, desde el punto de vista de los sujetos, la violencia que se expresa es una respuesta a las múltiples formas de violencia que vulneran sus derechos.

\section{Reflexiones finales}

A lo largo del artículo fue necesario "situar" (Nateras, 2016) las prácticas de los y las jóvenes de sectores populares de Villa Cañada, para comprender los matices que adquieren para ellos y ellas el entramados de violencias y los procesos de subjetivación en juego. Los modos en que se manifiestan los episodios violentos y la interrelación que subyace entre estas acciones y sus contextos, nos invitan a poner en relevancia la necesidad de estos análisis situados. Análisis que consideren los entramados de prácticas en los que estas acciones se configuran en su devenir. Consideramos que esta comprensión no puede hacerse "por fuera" de los mismos jóvenes, sino que implica entender y comprender junto a ellos sus códigos y sus coordenadas de sentido.

Hemos intentado fundamentar la idea de que la violencia se ubica en una tensión entre la desubjetivación y la subjetivación (Wie- 
viorka, 2006). En relación con la desubjetivación, adquieren relevancia los dispositivos policiales y territoriales, que se conjugan y articulan condicionando las vidas de los y las jóvenes a través del desprecio y la anulación de posibilidades de constitución subjetiva. Por otro lado, las búsquedas de reconocimiento y de instaurar alguna legalidad en estos contextos violentos, dan cuenta de un ejercicio de la violencia que se puede comprender como una práctica al servicio de una producción de subjetividad posible.

En esta línea de análisis, entendemos que las manifestaciones de violencia de los y las jóvenes de villa Cañada estarían actuando como "una señal", con el fin de ser visibilizados, en busca de un reconocimiento y como un modo de autoafirmación. Así, portar un arma, denigrar a otro, hacer frente a la policía en un acto de represión, emergen como atributos de una "subjetividad respetable", que no se doblega ante la estigmatización y la exclusión (Bourgois, 2010), ni ante las múltiples amenazas que le confiere el entorno. Para estos jóvenes "saber pararse" ante el otro, lograr el respeto, implica resguardar su dignidad.

En este punto, coincidimos con las críticas hacia quienes, embanderados en una "lucha contra la violencia", centran su mirada en los jóvenes de sectores populares como el prototipo de la clase peligrosa. Como sostiene Castel (2010), esta manera de abordar el asunto solo se convierte en una excusa en el tratamiento del tema. Plantearse un abordaje de la violencia en estos escenarios, requiere poner en relieve las múltiples conexiones que esta tiene con lo que, junto a Saraví (2006), podemos llamar sus "eslabones previos": las desigualdades a las que se enfrentan y la discriminación que padecen a diario en las diferentes facetas de sus vidas. Así como prevenir el desarrollo de nuevas desventajas de las cuales se les hace cada vez más difícil salir, ya que coartan sus posibilidades de integración social, sus proyectos futuros y la realización de expectativas (Cardozo, 2015).

En última instancia, y siguiendo el pensamiento de Nateras (2018), el trabajo con estos jóvenes, inmersos en la precariedad y la violencia cotidiana, nos invita a "volver a recuperar el valor de la vida social/comunitaria y, aunque pareciera que la existencia no vale nada y no tendría sentido - como cantaba José Alfredo Jiménez-, entonces hay que construirlo/edificarlo y apuntar - a pesar de todo- a que es viable la justicia social" (pp. 69-70). En este punto, el trabajo orientado a los y las 
jóvenes de sectores populares aún continúa siendo una deuda para las políticas que se erigen en pos de garantizar una verdadera inclusión.

\section{Bibliografía}

Auyero, J. y Berti, M. F. (2013). La violencia en los márgenes. Una maestra y un sociólogo en el conurbano bonaerense. Buenos Aires: Katz.

Bisig, E. (Comp.) (2014). Jóvenes y seguridad; control social y estrategias punitivas de exclusión. Código de Faltas Provincia de Córdoba. Córdoba: Universidad Nacional de Córdoba.

Bonvillani, A. (2015). 1 contra 364: ¿para qué sirve la Marcha de la gorra? En XI Jornadas de Sociología de la Universidad de Buenos Aires, Buenos Aires, Argentina. Recuperado de www. pensamientopenal.com.ar/system/files/2015/09/doctrina41926.pdf

Bourgois, P. (2001). The continuum of violence in war and peace: postcold war lessons from El Salvador. Ethnography, 2(1), 5-34.

Bourgois, P. I. (2010). En busca de respeto: vendiendo crack en Harlem. Buenos Aires: Siglo XXI Editores.

Cardozo, G. (2015). Violencias y desigualdades: un análisis a partir de la experiencia de los y las jóvenes en Córdoba (Argentina). Ponto-e-vírgula (17), 79-104. Recuperado de https:// revistas.pucsp.br/index.php/pontoevirgula/article/viewFile/27786/19618

Cardozo, G., Dubini, P. y González, A. S. (2019). Transición de jóvenes varones en conflicto con la ley penal hacia la vida adulta en Córdoba (Argentina). Psicología, Conocimiento y Sociedad, 1(9), 31-58. DOI: http://dx.doi.org/10.26864/PCS.v9.n1.6

Canal 10 Córdoba. (27 de octubre de 2015). Barranca Yaco: donde la normalidad es la exclusión (Archivo de video) Recuperado de https://youtu.be/JdV735LAAig

Castel, R. (2010). Robert Castel en la cátedra de UNESCO: Las transformaciones del trabajo, de la producción social y de los riesgos en un período de incertidumbre. Buenos Aires: Siglo XXI.

Castel, R. (2012). Prólogo. En G. Pérez Soto y M. Romero (Comp.). Futuros inciertos. Informe sobre vulnerabilidad, precariedad y desafiliación de los jóvenes en el conurbano bonaerense. Buenos Aires: Instituto Torcuato Di Tella. 
Castro, E. (2011) Diccionario Foucault. Temas, conceptos y autores. Buenos Aires: Siglo XXI.

Cervio, A. (2015). Del "barrio social" a las "ciudades-barrios". Programas habitacionales y elaboración de sensibilidades en la ciudad de Córdoba (Argentina) durante las décadas de 1980 y 2000. Methaodos. Revista de Ciencias Sociales, 3(2), 175-191.

Chaves, M. (2005). Juventud negada y negativizada: representaciones y formaciones discursivas vigentes en la Argentina contemporánea. Última década, (23), 9-32.

Chaves, M. (2010). Jóvenes, territorios y complicidades. Una antropología de la juventud urbana. Buenos Aires: Espacio editorial.

Comisión Provincial de la Memoria de Córdoba. (2015). Mirar tras los muros. Situación de los derechos humanos de las personas privadas de libertad en Córdoba. Tercer Informe de la Comisión de la Memoria.

Crisafulli, L. y León Barreto, I. (2011). ¿iCuánta falta!? Código de faltas, control social y derechos humanos. Córdoba: INECIP CBA.

Crisafulli, L. y León Barreto, I. (2015). Ritos y violencia en Córdoba. Los jóvenes y el Estado Penal. En M. Barrón y G. Borioli, Jóvenes cordobeses: de los márgenes al empoderamiento. Reflexiones sobre políticas (públicas) (pp. 202-213). Córdoba: SECyT, FFyH, UNC.

Crisafulli, L. (2014). El martillo y la policía: hacia la tolerancia cero y el racismo. En E. Bisig (Comp.), Jóvenes y seguridad; control social y estrategias punitivas de exclusión. Código de Faltas Provincia de Córdoba (pp. 177-198). Córdoba: Universidad Nacional de Córdoba.

Di Leo, P. F. (2011). Violencias, sociabilidades y procesos de subjetivación: un análisis de sus vinculaciones en experiencias de jóvenes en tres ciudades de Argentina. Persona y Sociedad, 4(14), 53-76. Recuperado de http://personaysociedad.cl/ ojs/index.php/pys/article/view/137/93

Di Leo, P. F. y Pinheiro, R. (2017). Vulnerabilidades y reconocimiento: abordaje biográfico de los vínculos entre jóvenes y violencias en barrios marginalizados de Buenos Aires, Argentina, Cadernos de Saúde Pública, 4(33). DOI: http://dx.doi. org/10.1590/0102-311x00200615.

Di Leo, P. y Camarotti, A. (2017). Relatos biográficos y procesos de individuación juveniles en barrios marginalizados de $\mathrm{Ar}$ - 
gentina. Revista Latinoamericana de Ciencias Sociales, Niñez y Juventud, 15(2), 1021-1034. DOI:10.11600/169271 5x.1521530082016.

Duschatzky, S. y Corea, C. (2002). Chicos en banda. Los caminos de la subjetividad en el declive de las instituciones. Buenos Aires: Paidós.

Foucault, M. (1988). El sujeto y el poder. Revista Mexicana de Sociología, 3(50), 3-20.

Foucault, M. (2007). Nacimiento de la biopolítica: Curso en el Collège de France: 1978-1979. Buenos Aires: Fondo de Cultura Económica.

Foucault, M. (2008). Historia de la Sexualidad 1. La voluntad del saber. Buenos Aires: Siglo XXI.

García Canclini, N., Cruces, F. y Urteaga, M. (2012). Jóvenes, culturas urbanas y redes digitales. Buenos Aires: Ariel.

Grinberg, S. (2015). Dispositivos pedagógicos, gubernamentalidad y pobreza urbana en tiempos gerenciales. Un estudio en la cotidianeidad de las escuelas. Propuesta educativa, 1(43), 123-130.

Krauskopf, D. (2005). Desafíos en la construcción e implementación de las políticas de juventud en América Latina. Nueva Sociedad, (200), 141-153. Recuperado de: https://www.nuso.org/ media/articles/downloads/3303_1.pdf

Lewkowicz, I. (2004). Pedagogía del aburrido. Escuelas destituidas, familias perplejas. Buenos Aires: Paidós.

Míguez, D. (2010). Los pibes chorros. Estigma y marginación. Buenos Ares: Edit. Capital Intelectual.

Ministerio de Trabajo, Empleo y Seguridad Social. Presidencia de la Nación. (2018). Provincia de Córdoba. Informe de diagnóstico laboral: julio de 2018. Buenos Aires: Dirección General de Estudios Macroeconómicos y Estadísticas Laborales. Recuperado de http://www.trabajo.gob.ar/downloads/estadisticas/ informesprovinciales/InfDiagLab_2018JUL_Cordoba.pdf.

Nateras, A. (2016). Mapas juveniles: $¿$ De la precariedad a la esperan$\mathrm{za}$ ? En A. Nateras (Coord.) Juventudes Sitiadas y Resistencias Afectivas (pp. 59-22). México: Gedisa.

Nateras, A. (2018). Geografías y mapas de las juventudes contemporáneas en México y América Latina. Revista SOMEPSO, 3(2), 54-73. 
Núñez, A. y Ciuffolini, M. A. (Comps.). (2011). Política y territorialidad en tres ciudades argentinas. Buenos Aires: El Colectivo.

Observatorio de Derechos Humanos del H. Senado de la Nación Argentina. (mayo de 2017). Observaciones Finales del Comité contra la Tortura sobre el quinto y sexto informe conjunto periódico de Argentina. Recuperado de: http://www.senado. gov.ar/bundles/senadomicrositios/pdf/observatorio/informe_comitecontratortura.pdf

Reguillo, R. (1999). Poderes sedentarios, narrativas itinerantes notas sobre políticas de identidad. Nómadas, (10), 228-238.

Reguillo, R. (2008). Las múltiples fronteras de la violencia: jóvenes latinoamericanos entre la precarización y el desencanto. Pensamiento Iberoamericano, (3), 205-225.

Represión en Barranca Yaco / Hay vecinxs detenidxs y heridxs. (26 de octubre de 2015). Mucho Palo Noticias. Recuperado de https://muchopalonoticias.com/2015/10/26/2640/

Saraví, G. (2006). Los eslabones de la violencia juvenil: Acumulación de desventajas en la transición hacia la adultez. En J. Moro (Ed.), Juventudes, violencia y exclusión: desafios para las políticas públicas (pp. 89-130). Guatemala: Magna Terra Editores.

Scribano, A. y Boito, E. (Comps.) (2010). El purgatorio que no fue: Acciones profanas entre la esperanza y la soportabilidad. Buenos Aires: Ciccus.

Techo, O. N. G. (2016). Relevamiento de asentamientos informales 2016. Informe recuperado de https://www.techo.org/argentina/ wp-content/uploads/sites/3/2019/04/Informe-Relevamiento-de-Asentamientos-Informales-2016-TECHO-Argentina.pdf

Uberti, O (2017). Violencia urbana y juventud en empalme Graneros Rosario, Argentina. Revista de estudios políticos y estratégi$\cos , 5(1), 132-151$.

Wieviorka, M. (2006) La violencia: destrucción y construcción del sujeto. Espacio Abierto, Asociación Venezolana de Sociología, (13), 239-248.

Zizek, S. (2009). Sobre la violencia: seis reflexiones marginales. Buenos Aires: Paidós. 